\title{
Morphological signs of merocrine secretion in the modified Sertoli cells of the domestic fowl (Gallus domesticus)
}

\author{
D. I. Osman* \\ Department of Anatomy and Histology, Faculty of Veterinary Medicine, \\ Swedish University of Agricultural Sciences, Uppsala, Sweden
}

\begin{abstract}
Summary. Testes of sexually mature White Leghorn cockerels were fixed by vascular perfusion with glutaraldehyde. Ultrastructural characteristics of the modified Sertoli cells typical of secretory activity included a large Golgi apparatus with dilated saccules, many smooth and coated vesicles, profiles of rough endoplasmic reticulum and dense granules surrounded by membranes in the Golgi area and in the basal and apical cytoplasm. Finely granulated dense bodies and some pinocytotic invaginations from the basal and lateral plasma membranes were also observed.
\end{abstract}

\section{Introduction}

A previous study on the terminal segment of the seminiferous tubules in the domestic fowl has shown that modified Sertoli cells possess features which suggest a secretory activity (Osman, 1980). Many reports have suggested, on morphological grounds, a secretory function (merocrine or apocrine secretion) for different types of cells in the male reproductive system of mammals, e.g. Sertoli cells (see Osman \& Plöen, 1978), cells of the epididymis (Nicander, 1970, 1979; Nicander \& Malmqvist, 1977), the prostate gland (Flickinger, 1974b; Nicander, Plöen \& Larsson, 1974) and the seminal vesicles (Flickinger, 1974a; Plöen, 1980). There has been little study of possible secretory phenomena in the reproductive system of the cockerel (Lake, 1957; Tingari, 1972).

In the present study the modified Sertoli cells of the domestic fowl were examined for evidence of secretory activity.

\section{Materials and Methods}

The testes from 6 sexually mature White Leghorn cockerels were used. The material was fixed by perfusion through the thoracic aorta by the technique described elsewhere (Osman, 1980). The fixative was $3 \%$ glutaraldehyde in $0.1 \mathrm{M}$-cacodylate buffer $(\mathrm{pH} 7.4)$. Small blocks of testicular tissue were cut from selected sites and secondarily fixed in $2 \%$ s-collidine-buffered osmium tetroxide for $3 \mathrm{~h}$. The blocks were then dehydrated in graded ethanols, cleared in propylene oxide and embedded in Epon. Semithin sections (about $1 \mu \mathrm{m}$ ), stained with toluidine blue buffered with s-collidine, were examined to identify the terminal segment of the seminiferous tubules. Thin sections were cut from the chosen areas, stained with uranyl acetate and lead citrate and examined in a Philips EM 201 tramsmission electron microscope.

* Present address: Department of Anatomy and Histology, Faculty of Veterinary Sciences, University of Khartoum, Khartoum North, P.O. Box 32 , Sudan. 


\section{Results}

The terminal segment of the seminiferous tubules was lined with modified Sertoli cells (Pl. 1, Fig. 1), the general uitrastructure of which has been described elsewhere (Osman, 1980). Evidence of a possible secretory function was seen. The cells possessed a prominent Golgi apparatus, mostly situated supranuclearly and in some instances between the nucleus and the basal plasma membranes. The supranuclear position of the Golgi apparatus varied, sometimes being close to the luminal border of the cell. The Golgi apparatus was in the form of several Golgi stacks (Pl. 2, Fig. 5) and each stack consisted of long curved or straight saccules. Some of the saccules contained material of low electron density. Usually the outermost saccules at one side of a stack were wider than the saccules of the other face of the same stack (Pl. 2, Fig. 4). Associated with the Golgi apparatus were many smooth, fuzz-coated and bristle-coated vesicles and some of these vesicles were in open connection with the saccules especially at their extremities (Pl. 2, Figs 4 and 5). Most of the fuzz- and bristle-coated vesicles contained a flocculent material of high electron density. Dense granules of different size and surrounded by a membrane were seen in the area of the Golgi apparatus (Pl. 2, Fig. 7). Similar granules occurred near the basal lamina and near the tubule lumen (Pl. 1, Fig. 2; Pl. 2, Fig. 8). Pinocytotic invaginations from the basal plasma membranes (Pl. 1, Fig. 2) and lateral plasma membranes were observed in a few instances. Dark bodies with finely granulated contents were observed mostly in the upper half of the cell (Pl. 1, Fig. 3). It was sometimes possible to identify a limiting membrane around these dark bodies. Long cisternae of rough endoplasmic reticulum were seen in the vicinity of the Golgi apparatus (Pl. 2, Figs 5 and 6). Short and dilated cisternae of granular reticulum were found in different parts of the cell, but mostly supranuclearly. The cisternae of rough endoplasmic reticulum contained opaque material. Smooth endoplasmic reticulum was not

\section{PLATE 1}

Fig. 1. A part of a terminal segment lined with modified Sertoli cells. The cells possess indented nuclei with prominent nucleoli, a sizable Golgi apparatus $(\mathrm{G})$ and many mitochondria. BT, boundary tissue. $\times 4000$.

Fig. 2. A basal portion of a modified Sertoli cell. Pinocytotic invaginations are indicated by arrows. Dense-cored vacuoles (arrow heads) and a centriole (C) are shown. BL, basal lamina; M, mitochondria. $\times 22000$.

Fig. 3. An apical part of a modified Sertoli cell showing a Golgi stack (G) with dilated saccules and coated vesicles (CV). Some dense bodies (arrow heads) with finely granulated matrix and a vacuole $(\mathrm{V})$ are indicated. $\times 25000$.

\section{PLATE 2}

Fig. 4. Golgi apparatus with the outermost saccules dilated. Smooth (SV) and coated (CV) vesicles and a mitochondrion $(\mathrm{M})$ with lamellar cristae are present in the Golgi area. $\times 15000$.

Fig. 5. Golgi apparatus in the form of many stacks. Each stack consists of dilated and fenestrated saccules and some coated vesicles (CV). A dense-cored vacuole is indicated by the upper arrow. Cisternae of rough endoplasmic reticulum (RER) contain opaque material. Intracytoplasmic sections of a sperm head and tail (arrow heads) can be seen. $\times 15000$.

Fig. 6. Part of supranuclear cytoplasm to show long cisternae of rough endoplasmic reticulum (RER), lipid droplets (LD) and free polysomes (P) in the Golgi area (G). A pinocytotic invagination (upper arrow) is seen at the lateral plasma membranes. The cisternae of endoplasmic reticulum contain opaque material. $\times 15000$.

Fig. 7. Some dense-cored vacuoles (granules) (arrows) are seen in the Golgi area. Some of the saccules of the Golgi apparatus are dilated. $\times 17500$.

Fig. 8. Apical part of a modified Sertoli cell to show some vacuoles (arrows) filled with electron-dense material near the luminal border. L, lumen. $\times 17000$. 
PLATE 1
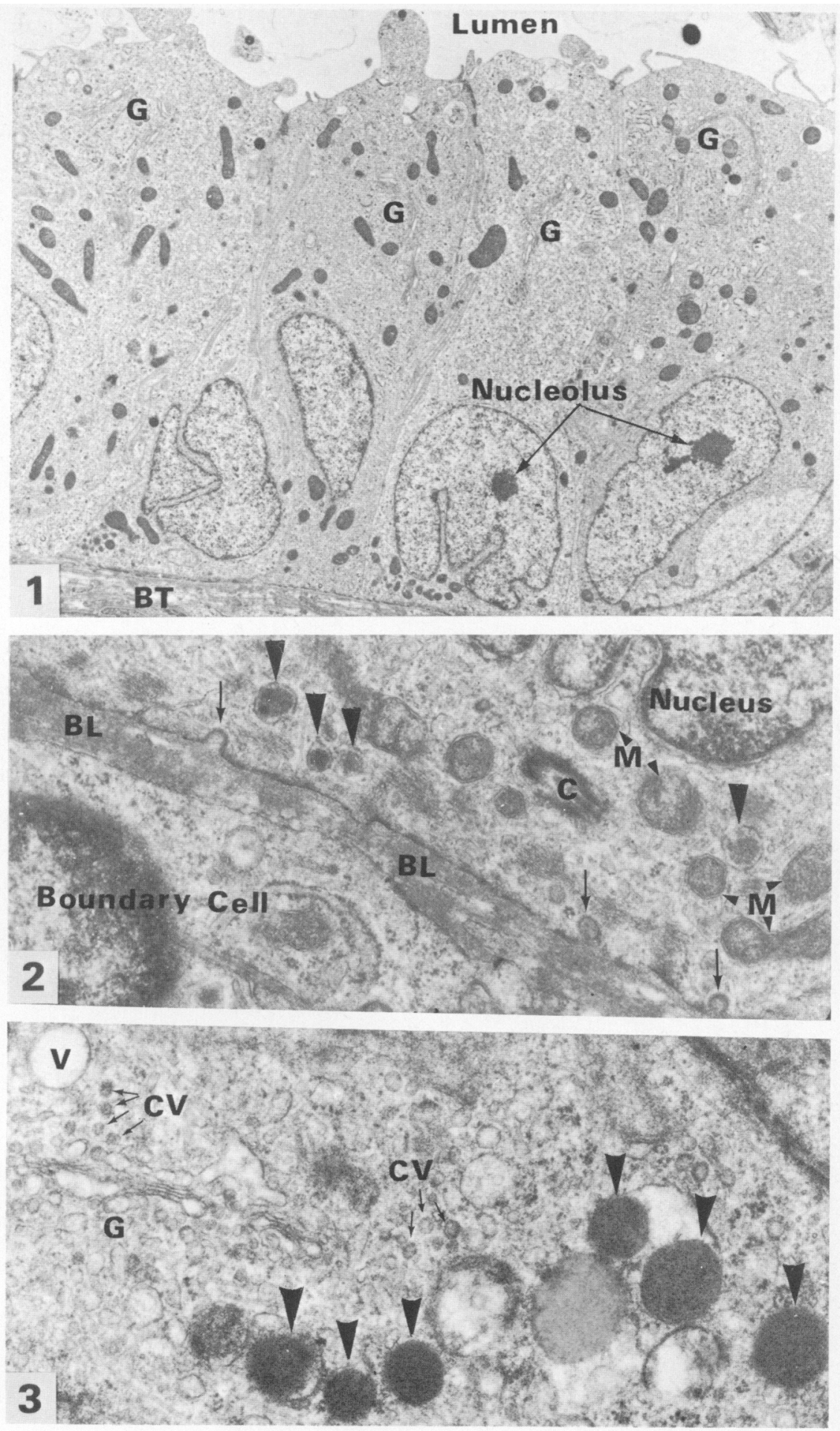

(Facing p. 76) 
PLATE 2
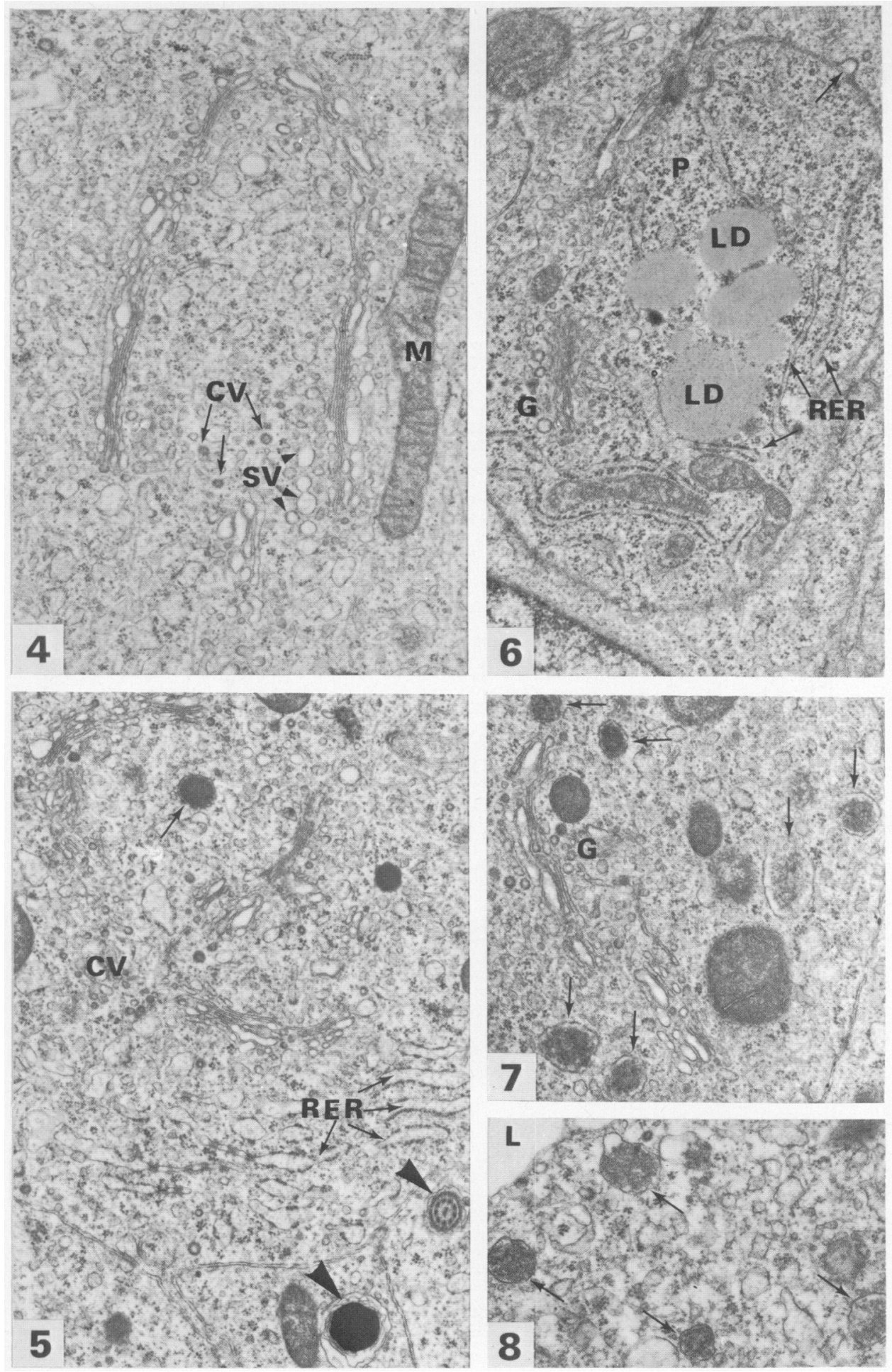
common and it was in the form of short and dilated vesicles. Free polysomes were common. Multivesicular bodies were observed in the Golgi area and towards the lumen. Mitochondria were commonly seen supranuclearly. The lamellar type of cristae was the dominant form. There were, however, variations amongst the cells regarding the amounts of the various organelles, especially rough endoplasmic reticulum and free polysomes.

\section{Discussion}

Gray (1937) stated that Sertoli cells of the seminiferous tubules continue to line the tubulus rectus which is currently called the terminal segment of the seminiferous tubules (see Osman, 1978). The cells lining the terminal segment are called modified Sertoli cells (Lake, 1957) and their general ultrastructure in the fowl has been described (Osman, 1980). Sertoli cells (see Cooksey \& Rothwell, 1973), modified Sertoli cells (Lake, 1957) and some of the cells in the excurrent duct system of the domestic fowl (Tingari, 1972) have features which suggest that they may be involved in secretory activities. In the present material, there are several features which are usually ascribed to a secretory process. These features include a well developed Golgi apparatus with dilated saccules, different types of vesicles and vacuoles and rough endoplasmic reticulum. Rough endoplasmic reticulum is involved in protein synthesis, the Golgi apparatus is supposed to add polysaccharide secretion and to package the secretory products, while vesicles and vacuoles are part of the shuttle of secretory products to the Golgi apparatus (see Palade, 1975). The modified Sertoli cells of the fowl, by analogy of their ultrastructure to that of secretory cell types, are possibly involved in a secretory activity. The secretion of the modified Sertoli cells is most probably proteinaceous. The Sertoli cells of the fowl are known to produce a lipoprotein-polysaccharide material (Lake, 1957). The domestic fowl has no accessory sex organs comparable to those of mammals (Lorenz, 1959), and it is therefore likely that some of the substances present in the semen (Lake, 1966; Lake \& El Jack, 1966) come from cells of the testis and/or its excurrent ducts. The membrane-bound granules seen in the modified Sertoli cells were found in the Golgi area and near the basal lamina and the tubule lumen. It is suggested that some of the secretory material is taken up by invaginations at the basal plasma membranes and that the membrane-bound granules formed are transported to the Golgi apparatus, possibly for addition of more material, and then secreted into the lumen.

I am grateful to the Swedish Institute for a guest scholarship.

\section{References}

Cooksey, E.J. \& Rothwell, B. (1973) The ultrastructure of the Sertoli cell and its differentiation in the domestic fowl (Gallus domesticus). J. Anat. 114, 329-345.

Flickinger, C.J. (1974a) Synthesis, intracellular transport and release of secretory protein in the seminal vesicles of the rat, as studied by electron microscope radioautography. Anat. Rec. 180, 407-426.

Flickinger, C.J. (1974b) Protein secretion in the rat ventral prostate and the relation of Golgi vesicles, cisternae and vacuoles, as studied by electron microscope radioautography. Anat. Rec. 180, 427448.

Gray, J.C. (1937) The anatomy of the male genital ducts in the fowl. J. Morph. 60, 393-405.

Lake, P. E. (1957) The male reproductive tract of the fowl. J. Anat. 91, 116-129.
Lake, P.E. (1966) Physiology and biochemistry of poultry semen. Adv. Rep. Physiol. 1, 93-123.

Lake, P.E. \& El Jack, M.H. (1966) The origin and composition of the fowl semen. In Physiology of the Domestic Fowl, pp. 44-51. Eds. C. Horton-Smith \& E. C. Amoroso. Oliver and Boyd, Edinburgh.

Lorenz, F.W. (1959) Reproduction in the domestic fowl: physiology of the male. In Reproduction in Domestic Animals, pp. 344-398. Eds. H. H. Cole \& P. T. Cupps. Academic Press, New York.

Nicander, L. (1970) On the morphological evidence of secretion and absorption in the epididymis. Morph. A spects Andrology 1, 121-124.

Nicander, L. (1979) Fine structure of principal cells in the initial segment of the epididymal duct in the ram. Zentbl. VetMed. C, Anat. Histol. Embryol. 8, $318-330$. 
Nicander, L. \& Malmqvist, M. (1977) Ultrastructural evidence of merocrine secretion in the initial segment of the mammalian epididymis. Cell Tiss. Res. 184, $487-490$.

Nicander, L., Plöen, L. \& Larsson, M. (1974) Specific apocrine secretion in the anterior lobe of the prostate gland of rabbits. Cell Tiss. Res. 151, 69-77.

Osman, D. I. (1978) On the ultrastructure of modified Sertoli cells in the terminal segment of seminiferous tubules in the boar. J. Anat. 127, 603-613.

Osman, D. I. (1980) The connection between the seminiferous tubules and the rete testis in the domestic fowl (Gallus domesticus): morphological study. Int. J. Androl. 3, 177-187.

Osman, D.I. \& Plöen, L. (1978) The ultrastructure of Sertoli cells in the boar. Int. J. Androl. 1, 162-179.

Palade, G. (1975) Intracellular aspects of the process of protein synthesis. Science, N.Y. 189, 347-358.

Plöen, L. (1980) Electron microscopic observations on the epithelium of the ram seminal vesicles. $J$. Anat. (in press).

Tingari, M.D. (1972) The fine structure of the epithelial lining of the excurrent duct system of the testis of the domestic fowl (Gallus domesticus). $Q$. Jl Exp. Physiol. 57, 271-295.

Received 11 March 1980 